\title{
Gl's genomics bid for secreted proteins
}

In late September, Genetics Institute (GI, Cambridge, MA), the American Home Products (Madison, NJ) subsidiary, announced its plans to mobilize a network of partner companies in the discovery and development of secreted protein therapeutics. Called "DiscoverEase" the collaboration's modest ambition, according to Tuan $\mathrm{Ha}-\mathrm{Ngoc}$, executive vice president, is " to create the largest product portfolio in history." In 5 to 10 years, he predicts "most protein therapeutics developed, or in development, will have come from this library and belong to this partnership."

Over the past 18 months, GI has investigated 39,000 genes, 5,000 of which code for novel secretory proteins. According to Clive Wood, senior scientist at GI, 250 full-length secretory proteins have now been isolated and expressed. GI anticipates the rest of the 5000 full-length cDNA clones will be identified over the next year.

The company is now offering its library of isolated and patented proteins to biotechnology and pharmaceutical companies through a "pay as you play" marketing strategy: Upfront costs are minimal, but as the protein proves its product potential, GI demands increasing financial returns. So far, two of the colossi of recombinant proteins, Genentech (S. San Francisco, CA) and Chiron (Emeryville, CA) have signed up. Dennis Henner, vice president of research at Genentech, noted that the technology would enable the company to find the subset of genes of most interest-those of secreted proteins. The major protein therapeutics on the market-insulin, interferons, erythropoietinare all secreted proteins.

According to Lewis "Rusty" Williams, senior vice president at Chiron, access to GI's library will complement and significantly extend Chiron's own internal research program for identifying secreted proteins. "Many other companies have been working on this type of technology-GI has just done a nice job of putting it all together," he noted.

GI identified and isolated the secretory proteins using a "signal sequence trap" (SST), part of GI's DiscoverEase functional genomics technology. In the SST system, cDNA libraries from a variety of tissue sources are linked to a secretion-defective gene in yeast that codes for invertase. If the cDNA contains a signal sequence, the yeast will secrete invertase and grow into a colony that can then be visually identified. The cDNA thus identified can then be used to isolate full-length cDNA clones that are

Sylvia Davidson is a freelance writer working in London. expressed to produce the recombinant secretory proteins. Industrial and academic collaborators receive the proteins in 96-well plates together with protein "pedigrees" information on cell and tissue sources, sequence, and protein expression data.

\section{In the next 5 to 10 years, Ha-Ngoc predicts "most protein therapeutics developed, or in development, will have come from the Genetics Institute library and will belong to this partnership."}

GI's strategy is to make the protein library available to as many researchers as possible, as companies like Incyte Pharmaceuticals (Palo Alto, CA), Human Genome Sciences (Rockville, MD), and SmithKline Beecham (King of Prussia, PA) have done with genetic sequence information. "Our premise," said $\mathrm{Ha}-\mathrm{Ngoc}$, "is that there are many bioassay systems out there and we are in no position to prejudge which ones are the best."

There is no upfront charge for accessing the library other than paying a fee-amounting to several hundred dollars-for each of the protein-containing 96-well plates. If a company then decides to take out an exclusive license on a protein, it can do so for a one-time cash payment that GI says is "modest" by industry standards. "[This] will encourage large biotech companies to participate," says Elizabeth Silverman, a genomics analyst at Punk, Zeigel \& Knoell (New York). "These are the companies that are very familiar with the commercialization of therapeutic proteins."

Once the protein starts to look like a product and begins its way through clinical trials, GI retains an option to codevelop the product by sharing $50 \%$ of both the costs and the profits. If GI does not exercise this option, it will still receive royalties-at an undisclosed percentage- on any protein product that is commercialized.

Analysts say pharmaceutical companies may balk at the prospect of setting aside $50 \%$ of future revenues to benefit a subsidiary of a major rival like AHP, even though many of the secretory proteins will be receptors and, therefore, potentially targets for small molecule development. But Patrick Gage, GI's chief operating officer, says a number of pharmaceutical companies have approached GI and are investigating a possible membership in the project.

Ha-Ngoc expects positive results in assays to be announced next year. GI already has "interesting" information on one protein in an in-house assay system, and both Chiron and Genentech began screening the proteins this year. Just how much this could be worth to GI is difficult to say. Adelene Perkins, business manager at GI, says that such a guessing game "would be like putting a figure on what the future biotech industry is worth... . [the revenue] is potentially enormous."

Sylvia Davidson

Additional reporting by Andrew Marshall

\section{Signal sequence traps}

The concept of specifically targeting secretory and membrane-bound proteins is not entirely new. A screen to identify secreted proteins based on the ability of cDNA clones encoding signal peptides to redirect the expression of an export-defective receptor to the surface of mammalian cells was reported by a Japanese group in 1993 (Science 261:6000-6003). But the signal sequence trap is based on selection rather than a screen, which significantly enhances the sensitivity and efficiency of pulling out secretory proteins. Not only does the system allow the simultaneous identification/isolation of many individual cDNAs from a large pool in a single step, but as little as $0.6 \%$ of the wild-type invertase activity is sufficient to allow growth on sucrose medium, allowing the detection of even the most inefficient mammalian signal peptide.

GI has not been alone in developing this technology; many other biotechnology companies, including Chiron and Genentech, have similar programs. Indeed, Robert Klein and colleagues, working in the departments of neuroscience and molecular biology at Genentech, published a paper describing the yeast invertase signal sequence trap in the July 8, 1996 issue of the Proceedings of the National Academy of Sciences (93:7108-7113), a mere eight days before GI's patent (US Patent $5,536,637$, July 16,1996 ) for the signal sequence trap was issued. Andrew Marshall 